EXTENDED REPORT

\title{
Socioeconomic status, occupation, and risk of hospitalisation due to coxarthrosis in Denmark 1981-99
}

\author{
F Tüchsen, H Hannerz, M V Jensen, N Krause
}

See end of article for authors' affiliations

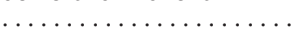

Correspondence to: Dr F Tüchsen, National Institute of Occupational Health, Lersø Parkallé 105, DK-2100 Copenhagen; ft@ami.dk

Accepted 11 March 2003

\begin{abstract}
Objectives: To predict the relative risk and time trend in hospitalisation due to coxarthrosis (CA) among groups of different socioeconomic status and occupations in order to test existing aetiological hypotheses. Methods: Four consecutive cohorts of all gainfully employed Danish men were followed up for CA. Standardised hospitalisation ratios (SHR) and time trends were calculated.

Results: Self employed men had an SHR due to CA of 140 (95\% confidence interval (CI) 130 to 151) in 1994-99. It changed $-1.2 \%(95 \% \mathrm{Cl}-2$ to -0.4$)$ annually from 1981 to 1999 . Self employed farmers had an SHR of $286(95 \% \mathrm{Cl} 262$ to 313$)$ during $1994-99$, increasing $0.14 \%$ a year $(95 \% \mathrm{Cl}-0.9$ to 1.1$)$ from 1981 to 1999. Unskilled men had an SHR of 121 (95\% Cl 113 to 130) in 1994-99. The SHR increased $1.6 \%$ annually (95\% Cl 0.7 to 2.4 ) from 1981 to 1999 . Employed agricultural workers had an SHR of 189 (95\% Cl 158 to 227) from 1994 to 1999. The SHR increased $3.7 \%$ annually $195 \% \mathrm{Cl} 1.2$ to 6.2) from 1981 to 1999.

Conclusions: The relative risk of hospitalisation due to CA was consistently high among farmers in four successive analyses spanning an 18 year period. The relative risks remained stable over time despite the fact that the number of farmers decreased. The risk increased among employed workers in agriculture and horticulture over that period, and an increased risk was also found among tractor drivers and a few other occupations.
\end{abstract}

A ccording to a Danish-Swedish study $40 \%$ of ideopathic cases of coxarthrosis (CA) can be attributed to physical workload, $55 \%$ to sports, and $15 \%$ to being overweight. ${ }^{1}$ Altogether the three factors account for $80 \%$ of CA. The calculations are based on a case-control study of 239 male recipients of a hip prosthesis and 302 men randomly selected from the general population. March and Bachmeier estimated the costs connected with musculoskeletal disorders, ${ }^{2}$ of which CA is the most common, to be $1-2.5 \%$ of the gross national product in Western industrialised countries. Clearly, identification of risk factors, monitoring of high risk groups, and prevention are very important public health issues. $^{3}$

Two reviews from 1997 conclude that there is an association between farming and $\mathrm{CA}^{3{ }^{4}}$ Lievense et al systematically reviewed two retrospective cohort and 14 case-control studies published between 1993 and April 2000 relating CA to the workload. ${ }^{5}$ Cases of CA were defined as patients with radiological and/or clinical CA, or a (total) hip replacement, or who were on the waiting list for one. The authors evaluated a possible publication bias by means of a funnel diagram of the odds ratios (OR) by sample size but found none. The studies included found ORs between 1.1 and 13.8. The OR varied between 2 and 14 in those studies in which the physical workload was farming. The six studies on heavy lifting reported ORs between 1.5 and 3.5 compared with no or low exposure to lifting heavy weights. The authors found moderate evidence for a threefold risk of heavy workload in patients with CA. They also found moderate evidence for a positive relationship between a history of farming and the occurrence of CA. Further evidence to support the part that jobs and occupational physical activities play in the occurrence of CA was recently reported by Schouten et al. ${ }^{6}$ Lau et al found increasing OR with body height, and a high OR in men with a history of joint injury $(\mathrm{OR}=25 ; 95 \%$ confidence interval (CI) 3.5 to 181$)$, and occupational exposure to walking, kneeling, climbing stairs frequently $(\mathrm{OR}=12.5 ; 95 \% \mathrm{CI} 1.5$ to 104$)$, and lifting $\geqslant 10 \mathrm{~kg}$ more than 10 times a week $(\mathrm{OR}=5.3 ; 95 \%$ CI 1.8 to 15.8$){ }^{7}$

A relatively old case-control study published in Swedish and not included in the reviews should be mentioned. ${ }^{8}$ Cases were 98 people with total hip replacement due to (CA). Ninety eight hospital controls with inguinal hernia and 202 population controls were included. Compared with the hospital controls the risk ratio in farmers was found to be 4.9 (95\% CI 3.0 to 8.1$)$. The author suggested that CA in farmers may be due to tractor driving in a twisted position. We will look at self employed in tractor pools to test that hypothesis. Also cow milking was associated with an increased risk (risk ratio $=1.8 ; 95 \%$ CI 1.1 to 3.4 ).

Interesting new hypotheses about specific work tasks of farmers are tested in a case-control study by Thelin et al, based on a cohort of farmers affiliated with the Swedish Farmers' Safety and Preventive Health Association. ${ }^{9}$ Despite a limited exposure contrast because all the controls were farmers too, they found strong and significant evidence for an association between CA and several occupational burdens. Farmers with larger dairy and swine confinement operations had an increased risk of acquiring OA of the hip. In a multivariate logistic regression model those who milked more than 40 cows daily had an increased risk (OR $=4.5 ; 95 \%$ CI 1.9 to 11.0 ) compared with those who did not work in dairy production. Those who had worked more than five hours daily in animal barns over a long period of time also had an increased risk $(\mathrm{OR}=13.3 ; 95 \%$ CI 1.2 to 145.0$)$ compared with those who did not work with animals. In another model those who had large farm areas (>100 ha) had a significantly decreased risk $(\mathrm{OR}=0.14 ; 95 \%$ CI 0.05 to 0.43$)$ compared with those who had smaller farm areas.

Abbreviations: $\mathrm{CA}$, coxarthrosis; $\mathrm{Cl}$, confidence interval; $\mathrm{OA}$, osteoarthritis; OR, odds ratio; SHR, standardised hospitalisation ratio 
Further evidence for the role of CA was found in a recent study of hip pain. ${ }^{10}$ Hip pain is both an antecedent and a symptom of CA, and the study showed that hip pain was predicted by obesity, physically demanding work, and self reported whole body vibrations five years earlier.

Although farming had already been reported to be associated with CA in 1966, ${ }^{11}$ we found no studies of time trends for different socioeconomic groups or specific occupational groups such as farmers. A Swedish study suggests that the prevalence of CA as seen on radiographs in subjects who have had a normal radiographic examination of the colon may be increasing. ${ }^{12}$ Because the division of farm labour has changed and employees are more exposed to whole body vibrations, twisted positions, and heavy physical labour for longer hours we suggest that more admissions to hospital due to CA will occur among employees in farming. If tractor driving is a risk factor, as has been suggested, we should find an increased risk among those working in tractor pools.

This study aimed at estimating the time trend in hospitalisation due to CA among different socioeconomic groups and groups with specific occupations by comparison of four successive cohorts. Another aim was to estimate the standardised hospitalisation ratio (SHR) for occupational groups in order to identify possible new occupational risk factors.

\section{MATERIAL AND METHODS}

All gainfully employed Danish men, aged 20-59 years in January 1981, 1986, 1991, and 1994, were classified according to their most important occupation in 1980, 1985, 1990, and 1993, respectively. These cohorts were followed up for first hospital admission with CA from 1981 to 1985, 1986 to 1990, 1991 to 1993, and 1994 to 1999, respectively.

This study uses first admissions in the follow up periods with the discharge diagnosis of International Classification of Diseases codes (ICD-8 $=713.00$ or ICD-10 $=$ M16). People with hip pain are usually only admitted to hospital if they seek and accept hip replacement surgery. According to population based surveys, only $15 \%$ of those with severe arthritis do so. ${ }^{13}$

All admissions to hospital and all deaths during the five, five, three, and six years of follow up, respectively, were recorded by linkage of the population census of Denmark to the national patient register and the death register. Coding of occupations was done by an employment classification module. The linked information is stored in the occupational hospitalisation register.

The national patient register and the death register The national patient register contains data on all admissions to public and private Danish hospitals (more than $99 \%$ of all admissions); it is updated every year. The personal identification number (PIN) from the national patient register was used in the crosslinking procedure.

\section{The central population register}

From the central population register information on sex, date, and year of birth was extracted. The central population register was used to identify all gainfully employed men who lived in Denmark on 1 January 1981, 1986, 1991, or 1994.

\section{The employment classification module}

The employment classification module contains information about economic activity, employment status, socioeconomic status, occupation, and industry. Employment status is a national code. The occupational code is an extended classification of the International Standard Classification of Occupations (ISCO) 1968 version, which also includes self employed men or from 1993 DISCO-88 (used in table 3). The industrial code is a national extension of the International Standard Classification of all Economic Activity (ISIC) 1968 version.

Everybody in Denmark older than 16 years of age is classified annually according to occupation in the employment classification module. From 1975 the employment classification module replaced the traditional survey based censuses. The data sources are several administrative registers. In Denmark the reportable financial transactions, including capital gains, salary, and wages, enable taxation authorities to preprint a tax declaration for each employee that is usually correct. A register for self employed people kept by the customs and taxation authorities holds additional information from independent enterprises. The Danish version of the 1988 ISCO classification (DISCO) of employees is also reportable for the employer. Registers of payments to the supplementary labour market pension fund, employment files for public employees, registers of graduation from various educational establishments, including education in the labour market, are all used in the classification of each person. Fixed criteria are used to handle inconsistencies between various sources of information.

\section{Validity of the basic information}

Year of birth and sex are parts of the PIN and are consequently recorded practically without errors. The completeness and accuracy of these data are shown by the fact that the matching of different registers by the PIN was 100\% complete. The primary data producers do not routinely check data on occupation, but information from various sources is compared and pooled together in the employment classification module. A recent thesis showed that $66.4 \%$ of the bus drivers occupied in Greater Copenhagen for more than six months in 1980, according to company personnel files, were also classified as employed by a bus company and as a bus driver in the classification of occupations. An additional 30\% had either the occupation or the industry code correct. It was shown that these misclassifications bias the risk estimate slightly towards unity. ${ }^{14}$ Farmers have an additional classification as an independent firm so the classification of occupation may be almost without errors.

The validity of the register based CA diagnosis was evaluated by one of the authors (MVJ) based on medical file abstraction of a complete sample of 110 hospitalisations occurring between 1987 and 1988 in a university hospital in Copenhagen. ${ }^{1516} \mathrm{~A}$ diagnosis was considered confirmed if it was based both on symptoms and on $x$ ray diagnosis according to the classification of diseases. A diagnosis was considered tentative if the basis was only a clinical examination without $x$ ray or surgery. Because a review of the symptoms and disease were present in the text it was not possible to blind the evaluator, who reassessed the diagnosis on basis of the entire medical file. The criteria were conservative because they are used to decide whether patients need surgery or not and whether surgery was recommended. Tentative diagnoses are not included in the occupational hospitalisation register.

\section{Analysis}

We calculated SHRs by dividing the observed number by the expected number of admissions to hospital in each cohort in a given occupation and multiplying it by 100 . The expected number was based on age-specific incidence rates for all gainfully employed men in Denmark. The counting of person-years at risk was censored at the date of first admission to hospital due to CA, emigration, or death, whichever came first.

Because the socioeconomic groups and the employment groups are large and the number of admissions due to CA is 


\begin{tabular}{|c|c|c|c|c|c|}
\hline \multirow[b]{2}{*}{ Socioeconomic status } & \multirow[b]{2}{*}{ People } & \multicolumn{2}{|c|}{ Annual change rate (\%) } & \multicolumn{2}{|c|}{ Predicted SHR } \\
\hline & & 1981-99 & $95 \% \mathrm{Cl}$ & 1994-99 & $95 \% \mathrm{Cl}$ \\
\hline $\begin{array}{l}\text { Self employed men } \\
\text { Managers } \\
\text { Senior salaried staff } \\
\text { Leading salaried staff } \\
\text { Other salaried staff } \\
\text { Skilled workers } \\
\text { Unskilled workers } \\
\text { Not economically active }\end{array}$ & $\begin{array}{r}159591 \\
5100 \\
162868 \\
170402 \\
198460 \\
267169 \\
332686 \\
192088\end{array}$ & $\begin{array}{r}-1.2 \\
1.6 \\
0.0 \\
1.7 \\
0.9 \\
1.2 \\
1.6 \\
0.1\end{array}$ & $\begin{array}{r}-2 \text { to }-0.4 \\
-3.9 \text { to } 7.0 \\
-1.5 \text { to } 1.6 \\
0.4 \text { to } 3.0 \\
-0.4 \text { to } 2.3 \\
0.1 \text { to } 2.4 \\
0.7 \text { to } 2.4 \\
-1.0 \text { to } 1.1\end{array}$ & $\begin{array}{r}140 \\
83 \\
56 \\
87 \\
96 \\
95 \\
121 \\
156\end{array}$ & $\begin{array}{l}130 \text { to } 151 \\
55 \text { to } 126 \\
50 \text { to } 63 \\
80 \text { to } 95 \\
87 \text { to } 106 \\
88 \text { to } 104 \\
113 \text { to } 130 \\
145 \text { to } 169\end{array}$ \\
\hline
\end{tabular}

low per person-year at risk, log-linear Poisson regression is an appropriate way to model the SHR, with interaction between employment group and time, and with the expected number of discharges as an offset. As time we used the distance in years between the midpoints of the follow up periods in each of the four cohorts. The model was applied to groups of different socioeconomic status and occupations. The parameters were estimated using SAS (SAS Institute Inc) Proc Genmod. The large-sample 95\% CIs were calculated using the estimated standard errors. Pearson's goodness of fit test ${ }^{17}$ was used to evaluate the appropriateness of the model assumptions. The model passed the test $(p=0.72$ for the analysis of occupations, $\mathrm{p}=0.79$ for the analysis of socioeconomic groups).

\section{RESULTS}

The diagnosis validation study showed that $98 \%$ of cases were correctly classified as 713.00, coxarthrosis (ICD-8 code). One case $(1 \%)$ was misclassified, as it should have been 713.01 arthrosis of the knee. One case (1\%) with the modification "obs. Pro." (under observation for) had minimal $x$ ray findings in disagreement with the symptoms.

Table 1 shows the association between socioeconomic status and admissions due to CA in 1994-99. Self employed men, unskilled workers, and people not economically active have a high risk of admission while senior salaried staff and leading staff have a low risk. We found a statistically significant decrease in SHR among self employed from 164 (95\% CI 152 to 177 ) in $1981-85$ to 140 (95\% CI 129 to 151 ) in the most recent period. Among skilled workers we saw an SHR increasing to 95 (95\% CI 88 to 104) in the most recent period. Among unskilled manual workers we saw an SHR increasing to 121 (95\% CI 113-130) in the most recent period. These figures need to be interpreted with caution because the measures are relative. Therefore changes in one group automatically imply changes in the others. In the earliest period 1981-85 the self employed farmers accounted for 32\% of the self employed men and as many as $70 \%$ of the cases in that group. In the most recent period self employed farmers accounted only for $21 \%$ of the self employed men and $53 \%$ of the cases in that group. The dramatic fall in the numbers of farmers may even explain some of the change in SHR among the unskilled workers and the other socioeconomic groups.

Table 2 shows SHR in agricultural occupations. We found a high relative risk of CA among self employed farmers who had a predicted SHR of 281 in the first follow up period, and 286 during 1994 to 1999. Among employed agricultural workers the predicted SHR increased from 114 in the first follow up period to 189 (95\% CI 158 to 227 ) in the most recent period. Among self employed in tractor pools we found an SHR of 210 in the first period. From 1994 to 1999 it was 183.

Figure 1 shows a stable triple risk of CA among self employed farmers $(0.14 \%$ average annual increase in the predicted SHR (95\% CI -0.9 to 1.1). Among employees (skilled and unskilled farm workers combined) we found an average risk at the start of the period but a high risk in the most recent periods. The increase in predicted SHRs was strong and statistically significant (3.7\% per year; 95\% CI 1.2 to 6.2 ).

Table 3 shows SHR for other occupations with statistically significant relative risks. Occupations with low risk can be

\begin{tabular}{|c|c|c|c|c|c|}
\hline Occupational category & Time period & $\begin{array}{l}\text { People at } \\
\text { risk }\end{array}$ & $\begin{array}{l}\text { Observed } \\
\text { number }\end{array}$ & SHR & $95 \% \mathrm{Cl}$ \\
\hline \multirow[t]{4}{*}{ Self employed farmers } & 1981-85 & 63990 & 458 & 281 & 259 to 304 \\
\hline & $1986-90$ & 52907 & 433 & 283 & 269 to 298 \\
\hline & $1991-93$ & 42825 & 213 & 285 & 268 to 302 \\
\hline & $1994-99$ & 34068 & 355 & 286 & 262 to 313 \\
\hline \multirow{4}{*}{$\begin{array}{l}\text { Self employed people in } \\
\text { agricultural tractor pools }\end{array}$} & 1981-85 & 1414 & 4 & 210 & 97 to 455 \\
\hline & $1986-90$ & 1365 & 6 & 200 & 122 to 327 \\
\hline & $1991-93$ & 1287 & 3 & 192 & 116 to 315 \\
\hline & 1994-99 & 1157 & 5 & 183 & 86 to 387 \\
\hline \multirow{4}{*}{$\begin{array}{l}\text { Employees in agriculture and } \\
\text { horticulture }\end{array}$} & $1981-85$ & 21811 & 37 & 114 & 89 to 147 \\
\hline & $1986-90$ & 21507 & 60 & 138 & 118 to 161 \\
\hline & $1991-93$ & 20351 & 33 & 160 & 140 to 183 \\
\hline & 1994-99 & 20734 & 97 & 189 & 158 to 227 \\
\hline
\end{tabular}




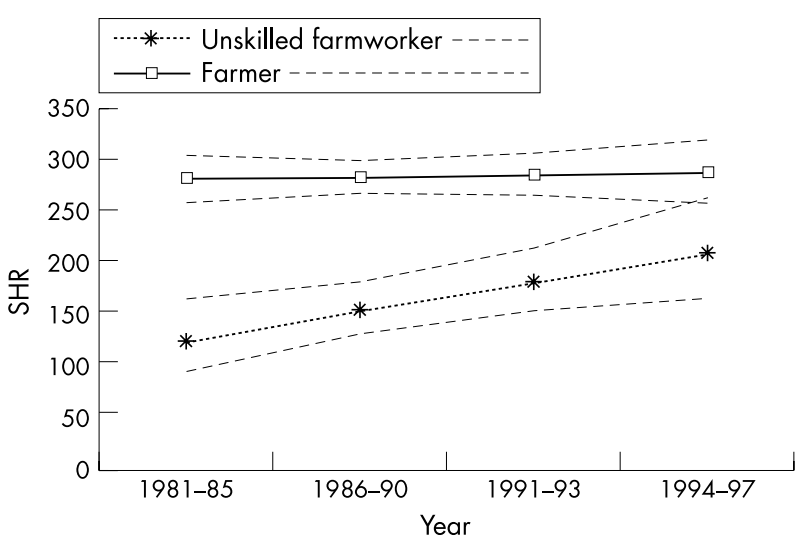

Figure 1 Time trends in predicted standardised hospitalisation ratios and $95 \%$ confidence intervals due to coxarthrosis among male self employed farmers and male employees in farming and horticulture.

characterised as white collar jobs performed mostly while sitting. High risk occupations can be described as blue collar jobs with exposure to vibrations, heavy lifting, walking, and standing work.

\section{DISCUSSION}

We found that the relative risk of admission to hospital due to CA was consistently high among farmers in four successive analyses spanning 19 years. These increased risks remained stable over time despite the fact that the number of farmers decreased significantly. The risk increased among employed workers in agriculture and horticulture over the same period. The results agree with reports of high risks found among farmers in the UK, ${ }^{18}{ }^{19}$ and in Sweden. ${ }^{120-24}$ We also found an increased risk in tractor drivers and a few other occupations. The relative high risk among self employed men in agricultural tractor pools is interesting because of the exposure to vibrations and work in a twisted posture. High risks found among other professional drivers also support the hypothesis that driving and whole body vibration contribute to the development of CA.

Our results are based on admissions to hospital due to CA in four consecutive cohorts of all gainfully employed men in Denmark. Referral bias is often a major problem in hospital based studies. It is, however, a methodological strength that all first hospital admissions due to CA in Denmark are included and that geographical distances are small even for farmers. It is also an advantage that admissions are free of charge. It was shown for ischaemic heart disease that only lower grade hospital staff had referral bias resulting in an excess SHR. ${ }^{25}$ If there were any effect of the referral system it should show up as a reduced risk in farmers because of the geographical distances and not as an excess risk. Population based studies show that only a small fraction of those with hip pain seek and accept hip replacement surgery. ${ }^{13}$ We cannot exclude the possibility that farmers and other groups who are very dependent on their mobility are more likely to accept hip replacement surgery, but Thelin suggest that the opposite may also happen: "The entrepreneurship and the family-farming situation very often force the farmer to delay a planned surgery." ${ }^{26}$ Neither can we exclude the possibility that an increasing load of heavy work among farm employees might motivate a higher proportion to accept hip replacement. On the other hand, many other groups have the same dependence on their mobility without having an increased relative risk of admission to hospital due to CA.

It is often difficult to choose a comparable reference group. We chose the entire gainfully employed male population as our standard in order to mitigate the healthy worker effect. We did not standardise for social class because CA seems to have more specific causes and because such standardisation tends to underestimate the true effects.

Vingård, et al argued that CA may remove people from their occupation a long time before they have a hospital diagnosis, and that a better point at which to measure occupation is 10 years before the start of follow up. ${ }^{23}$ To test this we selected men who had the same occupation in 1985 as they had in 1980 and followed them up for CA in the following five years. For all three occupational groups the corresponding SHR values were only one point higher or lower than for the entire cohort. Therefore we did not implement that restriction in the entire study because it would have prevented full use of the four consecutive cohorts.

A possible explanation for the high risk among agricultural occupations might be that more than $50 \%$ of all part time disability pensions are given to farmers, which implies that they continue to work despite some disability. In a study of 1283 male farmers and 334 male farm workers, Thelin et al found a lower risk of retiring due to health problems among

Table 3 Estimated age standardised hospitalisation ratio (SHR) for coxarthrosis among Danish men in occupations with significantly low or high SHR* $1994-99$ and $95 \%$ confidence intervals (Cl)

\begin{tabular}{lrrrrr}
\hline & People & Cases & Exp. & SHR & 95\% CI \\
\hline Electronics mechanics and servicers & 5920 & 1 & 8.1 & 12 & 0.3 to 68.7 \\
Business professionalst & 7442 & 6 & 21.2 & 28 & 10.4 to 61.7 \\
Buyers & 2963 & 3 & 9.2 & 33 & 6.7 to 95.1 \\
Teaching professionalst & 5658 & 4 & 10.7 & 37 & 10.2 to 95.4 \\
Medical doctors & 8959 & 11 & 24.1 & 46 & 22.8 to 81.6 \\
College, university, and higher education & 4502 & 8 & 16.6 & 48 & 20.8 to 94.9 \\
teaching professionals & & & & & \\
Agricultural or industrial machinery mechanics & 8716 & 9 & 18.1 & 50 & 22.7 to 94.3 \\
and fitters & & & & & \\
Architects, engineers, and related professionals† & 35751 & 47 & 87.2 & 54 & 39.6 to 71.7 \\
Armed forces & 27739 & 14 & 24.6 & 57 & 31.1 to 95.3 \\
Technical and commercial sales representatives & 21014 & 36 & 50.4 & 71 & 50.0 to 98.9 \\
Heavy truck and lorry drivers & 25879 & 82 & 60.3 & 136 & 108.1 to 168.8 \\
Motor vehicle drivers $\dagger$ & 9062 & 43 & 29.1 & 148 & 106.9 to 199.0 \\
Meat and fish processing machine operators & 13001 & 30 & 16.4 & 183 & 123.7 to 261.6 \\
Bakers, pastry cooks, and confectionery makers & 4487 & 20 & 9.8 & 204 & 124.5 to 314.7 \\
Waiters and bartenders & 3496 & 11 & 5.4 & 204 & 102.0 to 365.6 \\
Wood product machine operators & 6940 & 17 & 8.3 & 205 & 119.3 to 327.9 \\
Machine operators and assemblers† & 3367 & 16 & 7.7 & 207 & 118.3 to 336.2 \\
\hline
\end{tabular}

*Except those already shown in table 2; tnot elwhere classified. 
farmers but a higher relative risk among farm employees than in other occupationally active men in the same rural community. ${ }^{27}$ Therefore, removal from the workforce due to health may be less prevalent among farmers than in other occupations. Because our study did not include people aged over 60 at baseline, and because we have at least three years of follow up time, independent of current occupational status, we do not believe that health based early retirement in other occupational groups can explain our findings. The group of pensioners retiring at an early age had a risk nearly as high as that of the farmers: in the period 1994-99, 434 cases of "early age" pensioners had an SHR of 174 (95\% CI 158 to 191$)$.

One might speculate that farmers are more active in sports. Thelin et al suggested this might be a confounding factor. ${ }^{9}$ They had no data about sports activities, however. We have recently collected data for the Danish Work Environment Cohort (a national representative survey carried out every five years) and found that only one third of self employed farmers in the year 2000 were physically active in leisure time for more than four hours a week compared with $42 \%$ of all occupationally active men. In conclusion, we find it unlikely that any selection bias or confounding could explain the consistent pattern of a stable high relative risk among farmers and the increasing relative risk among skilled and unskilled agricultural workers.

The increasing risk among farm employees may be partially explained by the concentration in farming. The number of farms (and self employed farmers) has dropped dramatically from 64000 in 1980 to 34000 in 1995. The number of farm workers is almost the same (17 500) but the average number on each farm has increased accordingly. Because there are fewer farmers and they function more as managing directors, the farm workers have taken over the ploughing, which may be the worst hip loading work, and other heavy physical work as well. The standing work in connection with milking is now often four hours compared with only one hour some years ago when a typical farm had only 40-50 cows. In addition, many other functions have become specialised, meaning that a worker is doing the same task for longer periods and is therefore relatively more exposed to repetitive strains (Hjort C, personal communication).

The pathogenesis of osteoarthritis (OA) is not entirely known, although many different workloads have been suggested in the aetiology of CA. Thelin suggested that driving a tractor in a twisted posture may contribute to the disease and loads from heavy lifting and walking on rough ground. ${ }^{822} 28$ Jacobsson et al reported an increased incidence of heavy labour, farming, heavy lifting, and tractor driving among patients with CA (defined as being on the waiting list for total hip replacement or having a joint space $<3 \mathrm{~mm}$ ). ${ }^{24}$ Our results for people employed in tractor pools give some support to the hypothesis that tractor driving is a high risk factor of CA. The risk we found among farmers was, however, higher than among tractor pool owners. This might imply that tractor driving is not the only or the main cause of CA among farmers. These results do not give any indication of whether a high risk of CA is due to driving in a twisted position or due to vibrations, heavy lifting, or two or more of these causes.

Sisto et al were surprised to find an association between OA and varicose veins. ${ }^{29}$ We suggest that prolonged standing may be the common causal factor. ${ }^{30}$ We find support for this hypothesis in the high risk of CA we found among meat and fish processing operators, bakers, pastry cooks and confectionery makers, waiter and bartenders, wood product machine operators and machine operators and assemblers. Such an explanation is also in accordance with findings by
Cvijetic et al, who found a strong association between radiological signs of hip arthritis and standing at work for men. ${ }^{31}$ In this Croatian-British study, 292 women and 298 men who did not have rheumatoid arthritis or gout were asked detailed questions on their occupational history, including load on the hip (hours spent sitting, standing, walking, and lifting heavy objects). The authors conclude that prolonged standing may influence the development of CA. They suggest that prevention of prolonged standing may reduce the incidence of $\mathrm{CA}$.

A recent Japanese case-control study found a significant OR of 3.6 of CA among people regularly lifting $\geqslant 25 \mathrm{~kg}$ or more during their first employment and an OR of 4.0 among workers lifting $\geqslant 50 \mathrm{~kg}$ in their main job. ${ }^{32}$ Lau et al found that Chinese men who lifted $\geqslant 10 \mathrm{~kg}$, more than 10 times a week had fivefold risk of CA and the risk was 10-fold if they lifted $\geqslant 50 \mathrm{~kg} .{ }^{7}$ Two other studies found a strong association between lifting and $\mathrm{CA}^{33}{ }^{34}$ and a clear chronological order between exposure and effect support a causal interpretation of this finding.

Hip pain is both an antecedent and a symptom of CA, and a recent study showed that hip pain can be predicted by obesity, physically demanding work, and whole body vibrations five years earlier. ${ }^{10}$ The idea that vibrations may have a role in the causation of $\mathrm{OA}$ is not new, but documentation is sparse. According to a review by Felson, OA of the elbow, shoulder, and wrist joints was, however, already associated with vibrations from Jackhammer vibrations before the second world war. ${ }^{35}$

Our finding of a stable high relative risk of CA among the self employed and a rapidly increasing risk among farm employees clearly indicates the need for a focused intervention strategy. Such a strategy may include identification and reduction of the suspected exposures: heavy lifting, prolonged standing, whole body vibrations, heavy physical work, tractor driving in a twisted posture, and much walking, especially on rough ground.

Our data support the hypothesis that professional driving may play a part in the aetiology of CA because we found a high risk of the disease among the self employed in tractor pools and among heavy lorry and truck drivers. We also found an increased risk among employees whose jobs required much walking and standing, such as waiters and machine operators.

In conclusion, we have found, firstly, that the relative risk of admission to hospital due to CA was consistently high among farmers in four successive analyses spanning a 19 year period; secondly, that these increased risks have remained stable over time despite the fact that the number of farmers has decreased; thirdly, the risk increased among employed workers in agriculture and horticulture over that time period; and fourthly, we also found an increased risk in tractor drivers and a few other occupations.

\section{ACKNOWLEDGEMENTS}

The Danish Health Insurance Fund financed this study: grant 2002B117. The authors are indebted to Otto Andersen, Statististics Denmark and to Jørgen Jørgensen, the National Board of Health for their help with the access and linkage of the original data. We are also indebted to former managing director of the industrial health service for agriculture, Charlotte Hjort, for her information about changing work conditions in farming.

\section{Authors' affiliations}

F Tüchsen, H Hannerz, M V Jensen, Department of Epidemiology and Surveillance, National Institute of Occupational Health, Denmark $\mathrm{N}$ Krause, Department of Medicine, Division of Occupational and Environmental Medicine, University of California at San Francisco, USA 


\section{REFERENCES}

1 Olsen $O$, Vingård E, Köster M, Alfredsson L. Etiologic fractions for physical work load, sports and overweight in the occurrence of coxarthrosis. Scand J Work Environ Health 1994;20:184-8.

2 March LM, Bachmeier CJ. Economics of osteoarthritis: a global perspective. Baillieres Clin Rheumatol 1997:11:817-34.

3 Maetzel A, Makela M, Hawker G, Bombardier C. Osteoarthritis of the hip and knee and mechanical occupational exposure-a systematic overview of the evidence. J Rheumatol 1997;24:1599-607.

4 Bøggild H, Johansen JP. Arbejdsmiljø og slidgigt i hoften. En oversigt over epidemiologiske undersøgelser af sammenhæengen mellem arbejdsmiliø og coxarthrosis (in Danish with a summary in English). [Work environment and osteoarthrosis of the hip.] Ugeskr Laeger 1997;159:4370-6.

5 Lievense A, Bierma-Zeinstra S, Verhagen A, Verhaar J, Koes B. Influence of work on the development of osteoarthritis of the hip: a systematic review. J Rheumatol 2001;28:2520-8.

6 Schouten JSAG, de Bie RA, Swaen G. An update on the relationship between occupational factors and ostearthritis of the hip and knee. Curr Opin Rheumatol 2000;14:89-92.

7 Lau EC, Cooper C, Lam D, Chan VN, Tsang KK, Sham A. Factors associated with osteoarthritis of the hip and knee in Hong Kong Chinese: obesity, joint injury, and occupational activities. Am J Epidemiol 2000;152:855-62.

8 Thelin A. Höftledsartros vanlig åkomma bland lantbruksarbetare (in Swedish). [Coxarthrosis is common among farm workers.] Läkartidningen 1985:82:3994-9.

9 Thelin A, Vingård E, Holmberg S. Osteoarthritis of the hip joint and farm work. Am J Ind Med, (in press).

10 Tüchsen F, Hannerz H, Burr H, Lund T, Krause N. A five-year prospective cohort study of risk factors predicting hip pain. Scand J Work Environ Health 2003;29:35-9.

11 Louyot P, Savin R. La coxarthrose chez l'agriculteur. Revue de rheumatisme 1966;33:625-32.

12 Danielsson L, Lindberg $\mathrm{H}$. Prevalence of coxarthrosis in an urban population during four decades. Clin Orthop 1997:106-10.

13 Hawker GA, Wright JG, Coyte PC, Williams JI, Harvey B, Glazier R, et al. Determining the need for hip and knee arthroplasty: the role of clinical severity and patients' preferences. Med Care 2001;39:206-16.

14 Bach E. Validering af EIR - Et arbejdsepidemiologisk moniteringssystem (In Danish with a summary in English). [Validation of OHR - a work environmental information system.] Roskilde Universitetscenter, Arbejdsmiliøinstituttet, 1998:1519-23, (Thesis).

15 Jensen MV, Tüchsen F. Erhverv og diskusprolaps i lænden (In Danish with a summary in English). [Occupation and lumbar disc prolapse.] Ugeskr Laeger 1995: 157:1519-23.

16 Jensen MV, Tüchsen F, Bach E. Erhvervsindlæggelsesregistret. 1. Det ny register. 2. Erhverv og bevægeapparatsygdom (in Danish). [The occupational hospitalization register,] Copenhagen: Arbejdsmiliøfondet, 1994
17 Larsen RJ, Marx ML. An introduction to mathematical statistics and its applications. Englewood Cliffs, New Jersey: Prentice-Hall, 1986.

18 Croft P, Cooper C, Wickham C, Coggon D. Osteoarthritis of the hip and occupational activity. Scand J Work Environ Health 1992;18:59-63.

19 Croft P, Coggon D, Cruddas M, Cooper C. Osteoarthritis of the hip: an occupational disease in farmers. BMJ 1992;304:1269-72.

20 Axmacher B, Dahlsjo L. A new method to measure rotation in the hip joint. J Occup Med 1985;27:236-7.

21 Axmacher B, Lindberg H. Coxarthrosis in farmers. Clin Orthop 1993:82-6.

22 Thelin A, Jansson B, Jacobsson B, Strom H. Coxarthrosis and farm work: a case-referent study. Am J Ind Med 1997:32:497-501.

23 Vingård E, Alfredsson L, Goldie I, Hogstedt C. Occupation and osteoarthrosis of the hip and knee: a register-based cohort study. Int J Epidemiol 1991;20:1025-31.

24 Jacobsson B, Dalen N, Tiornstrand B. Coxarthrosis and labour. Int Orthop 1987;11:311-13

25 Tüchsen F, Andersen O, Olsen J. Referral bias among health workers in studies using hospitalization as a proxy measure of the underlying incidence rate. J Clin Epidemiol 1996:49:791-4.

26 Thelin A. Hip joint arthrosis: an occupational disorder among farmers. Am J Ind Med 1990;18:339-43.

27 Thelin A, Hoglund S. Change of occupation and retirement among Swedish farmers and farm workers in relation to those in other occupations. A study of "elimination" from farming during the period 1970-1988. Soc Sci Med 1994;38: 147-51

28 Thelin A. Work and health among farmers. A study of 191 farmers in Kronoberg county, Sweden. Scand J Soc Med Suppl 1981;22:1-126.

29 Sisto T, Reunanen A, Laurikka J, Impivaara O, Heliövaara M, Knekt P, et al. Prevalence and risk factors of varicose veins in lower extremities: mini-Finland health survey. Eur J Surg 1995;161:405-14.

30 Tüchsen F, Krause N, Hannerz H, Burr H, Kristensen TS. Standing at work and varicose veins. Scand J Work Environ Health 2000;26:414-20.

31 Cvijetic S, Dekanic-Ozegovic D, Campbell L, Cooper C, Potocki K. Occupational physical demands and hip osteoarthritis. Arh Hig Rada Toksikol 1999:50:371-9.

32 Yoshimura N, Sasaki S, Iwasaki K, Danjoh S, Kinoshita H, Yasuda T, et al. Occupational lifting is associated with hip osteoarthritis: a Japanese casecontrol study. J Rheumatol 2000;27:434-40.

33 Coggon D, Kellingray S, Inskip H, Croft P, Campbell L, Cooper C. Osteoarthritis of the hip and occupational lifting. Am J Epidemiol 1998; 147:523-8

34 Croft $\mathrm{P}$, Cooper C, Wickham C, Coggon. Defining osteoarthritis of the hip for epidemiologic studies. Am J Epidemiol 1990;132:514-22.

35 Felson DT. Do occupation-related factors contribute to arthritis? Baillieres Clin Rheumatol 1994:8:63-77. 